\title{
Assessment of Paramount Source of Oral Health Information among Outpatients Attending Dental College in Bengaluru, Karnataka, India: A Cross-sectional Survey
}

\author{
Ajitha Kanduluru ${ }^{1}$, Manasa Srinivas ${ }^{2}$, Shweta H Lingaraj ${ }^{3}$, Suma B Adapa ${ }^{4}$, Mayura Tonpe ${ }^{5}$, JayaKumar H Lakkappa ${ }^{6}$
}

\begin{abstract}
Introduction: Health communication is a process necessary to inform individuals pave way toward desired changes in human health behavior and contribute community participation to achieve predetermined health goals. Hence, the present study aims to assess the paramount source of oral health information among outpatients attending one of the dental colleges in Bengaluru city.

Materials and methods: A cross-sectional survey was conducted among 1,800 outpatients attending Vydehi Dental College, Bengaluru, during a period of 1 month (November 1-31, 2011). A self-structured close-ended questionnaire was used to collect data about demographic details and their source of information regarding oral health. Data were analyzed by Chi-square test using SPSS version 21.

Results: Among the total study population, highest percentages (28.0\%) of them were between the age group of $26-35$ years, $56 \%$ of them were male, $32.0 \%$ of them were graduates, and $25.5 \%$ of them were clerical. In the present study, the major source of oral health information was parents $(21.1 \%)$, followed by friends $(20.1 \%)$, television $(19.5 \%)$, and grandparents $(16.6 \%)$. Study shows highly significant association ( $p$ value $=0.001)$ for all questions with respect to gender, age, occupation, and education .

Conclusion: It can be concluded that the parents, peers, and media are the paramount source for the oral health information among the study population. Hence, there is a need to target these groups to reinforce the oral health education.

Keywords: Health communication, Media, Parents, Source of information.

Journal of Oral Health and Community Dentistry (2019): 10.5005/jp-journals-10062-0056
\end{abstract}

\section{INTRODUCTION}

Oral health is fundamental to general health and well-being, significantly impacting on quality of life. Oral health enables an individual to speak, eat, and socialize without active disease, discomfort, or embarrassment in both developing and developed countries. Oral diseases are major public health problems especially effecting underprivileged groups. Dental caries, periodontal diseases, and oral cancer are the leading oral diseases occurring worldwide. ${ }^{1}$ Communication is more than mere exchange of information. It is a process necessary to inform individuals pave way toward desired changes in human behavior and to contribute community participation to achieve predetermined goals.

Health communication is an important area of communication. The primary function of this is to provide scientific knowledge or information to people about health problems and how to maintain and promote health. When the message relayed via mass media gets diffused into the community, it is picked up by the interpersonal and informal networks. The message is then subject to debate and discussion by interpersonal communication. On the basis of this scrutiny, a consensus is gradually built-up in the community whether to accept or reject the message. ${ }^{2}$

Oral health education is an integral part of community-oriented preventive programs. Oral health education is believed to be a costeffective method for promoting oral health if done through schools, where all schoolchildren irrespective of their socioeconomic status or ethnicity can be reached. Evidence has showed that an increase in knowledge about risk factors for oral disease and strong knowledge of oral health demonstrates better oral care practices that aim to promote healthy habits.
1,5,6 Department of Public Health Dentistry, Syamala Reddy Dental College, Hospital and Research Centre, Bengaluru, Karnataka, India

2,3 Department of Public Health Dentistry, Vydehi Institute of Dental Sciences and Research Centre, Bengaluru, Karnataka, India

${ }^{4}$ Department of Public Health Dentistry, AECS Maruthi Dental College, Bengaluru, Karnataka, India

Corresponding Author: Ajitha Kanduluru, Department of Public Health Dentistry, Syamala Reddy Dental College, Hospital and Research Centre, Bengaluru, Karnataka, India, Phone: +91 9900011992, e-mail: ajithareddy27@gmail.com

How to cite this article: Kanduluru A, Srinivas M, Lingaraj SH, et al. Assessment of Paramount Source of Oral Health Information among Outpatients Attending Dental College in Bengaluru, Karnataka, India: A Cross-sectional Survey. J Oral Health Comm Dent 2019;13(3): 101-105.

Source of support: Nil

Conflict of interest: None

The critical approach to health education considers that economic, social, and cultural factors are the principal determinants of disease. The responsibility for unhealthy behavior lies with society, not with the individual. Thus, education programs targeted at the individual, aiming to change an unhealthy conduct, will be a complete failure if they do not consider the different aspects of the subject's life both socioeconomical and environmental, which influences their behavior and are responsible for diverse health problems.

Though there are several audiovisual aids used in mass media to educate people or pass the information about oral health care, family plays a major role in everyone's life as they will be in

() The Author(s). 2019 Open Access This article is distributed under the terms of the Creative Commons Attribution 4.0 International License (https://creativecommons. org/licenses/by-nc/4.0/), which permits unrestricted use, distribution, and non-commercial reproduction in any medium, provided you give appropriate credit to the original author(s) and the source, provide a link to the Creative Commons license, and indicate if changes were made. The Creative Commons Public Domain Dedication waiver (http://creativecommons.org/publicdomain/zero/1.0/) applies to the data made available in this article, unless otherwise stated. 
close contact from birth. As age increases, people could also be influenced by peers, books, internet, and television, etc. In parallel with evaluation of oral health knowledge, several researchers identified different sources of oral health information, such as parents, school teachers, dentists, and media which have a direct influence on the oral health knowledge of schoolchildren, which in turn influences their oral health status. Therefore, documentation of primary source of oral health information is needed. ${ }^{3}$

If we know the paramount source for oral health information, we can provide health education and can design an effective preventive program and bring changes in oral health behavior by targeting the group.

Hence, the present study aims to assess the paramount source of oral health information among outpatients attending one of the dental colleges in Bengaluru city.

\section{Materials and Methods}

A cross-sectional survey was conducted over a period of 1 month (i.e., November 1-31, 2011) at Institute of Dental Sciences and Research Centre, Bengaluru. Around 1,800 outpatients were included in the study during that period who met inclusion and exclusion criteria. A pretested, structured, self-administrated questionnaire in local language was used to collect data regarding their demographic details and their source of information about oral health.

The questionnaire contained seven multiple-choice closedended questions regarding source of information about brushing technique, tooth decay, periodontal problems, and oral cancer. Ethical clearance was obtained from Ethical Review Board, dental college and hospital, and written informed consent from the participants.

A pilot study was conducted in 40 dental outpatients to check the reliability and validity of the questionnaire. Reliability of the questionnaire was found to be good with a Cronbach's alpha of 0.9 .
This study included new patients attending outpatient department and aged above 18 years. All medical and paramedical personnel, chronically ill with systemic disease patients, and people who were not willing to participate/not given written informed consent were excluded from study.

\section{Data Collection}

The questionnaire was self-administered by giving required instructions to the participants and collected back with written informed consent from them. They were given sufficient time to fill the questionnaire. Data collection was supervised by the investigator and collected after completion. Sufficient time was allotted for completion of the questionnaire.

\section{Statistical Analysis}

Data were analyzed using statistical package SPSS 21 version (IL, Chicago). Chi-square test was used to assess the paramount source of oral health information in association with demographic details. Significance level was fixed at $p<0.05$.

\section{Results}

The response rate was good in this study (97\%), giving further strength to the validity of the study. Fifteen members were excluded from the study as they were not willing to participate and 35 were excluded from analysis because the questionnaire was not completely filled by them. Hence, the sample was 1,750.

Figures 1 and 2 and Table 1 show the demographic details of the study population. Among the total study population, highest percentages (28.0\%) of them were between the age group of 26-35 years, $56 \%$ of them were male, $32.0 \%$ of them were graduates, and $25.5 \%$ of them were clerks.

Table 2 shows the descriptive statistics about paramount source of oral health information among the total study population. The major source of information regarding brushing technique was found in this study was parents (55.2\%). The major

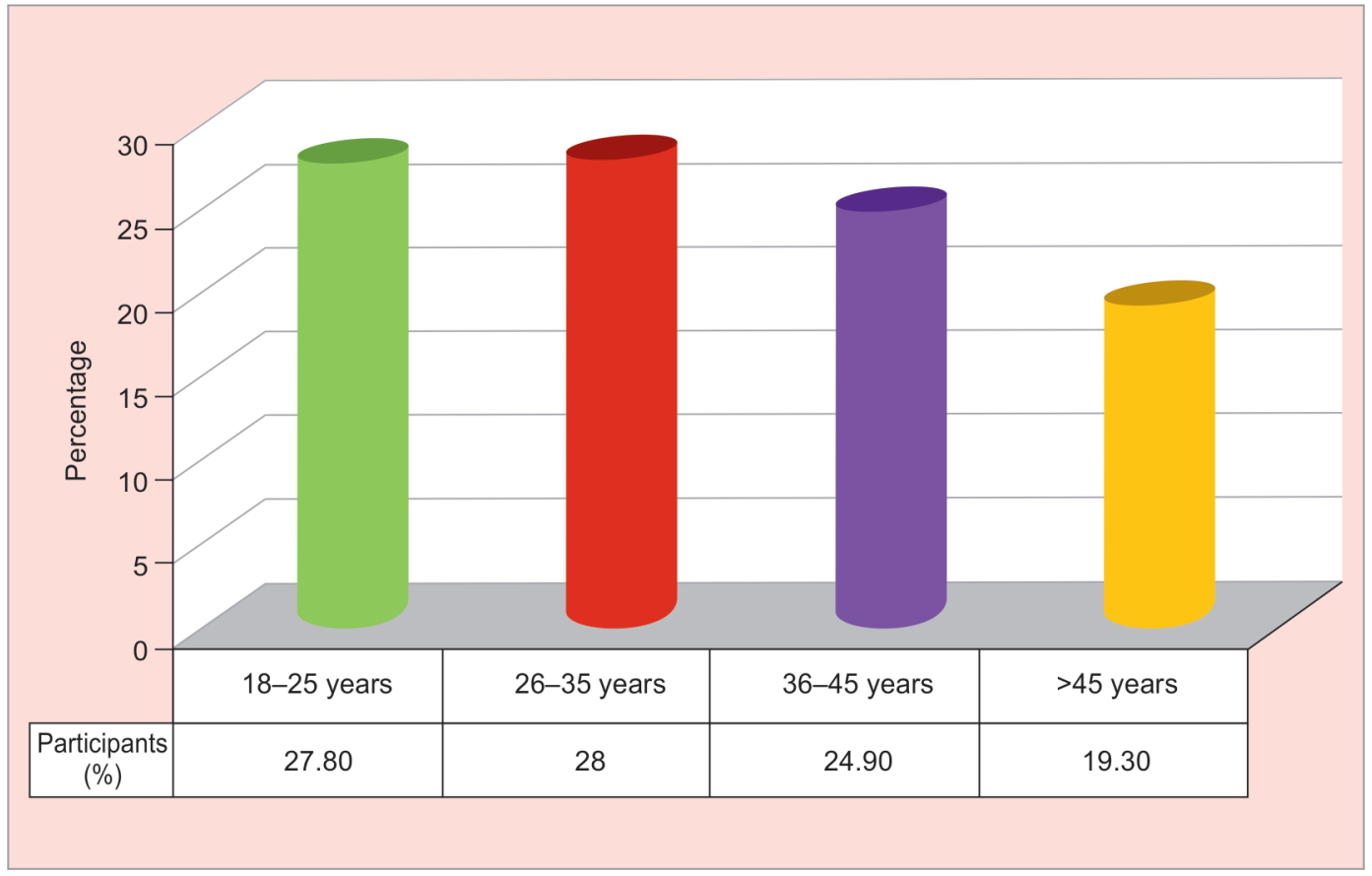

Fig. 1: Age distribution of study participants 


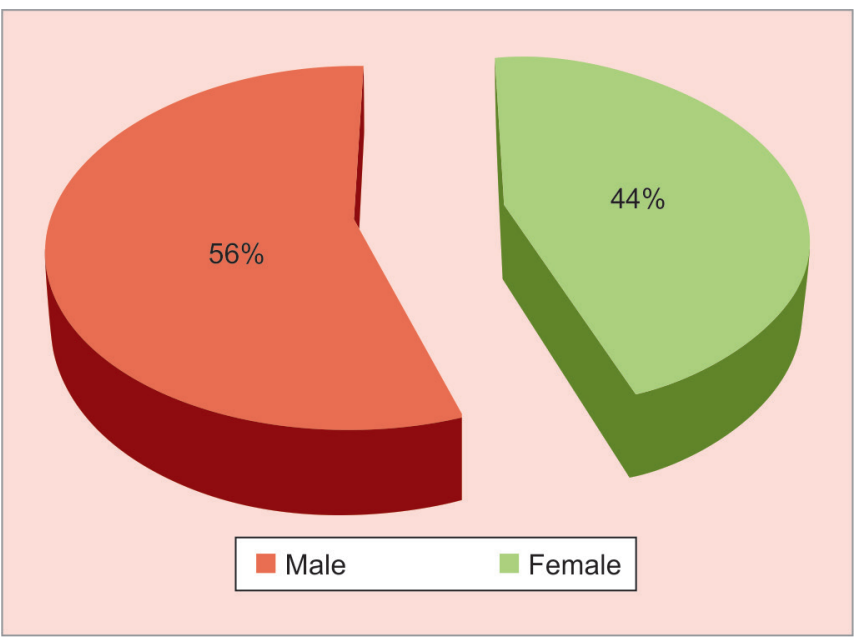

Fig. 2: Genderwise distribution of participants

Table 1: Education and occupation details of the study population

\begin{tabular}{llc}
\hline Variables & $\begin{array}{l}\text { Study population } \\
(n=1,750)\end{array}$ & Percentage \\
\hline Education & & \\
Illiterate & 261 & 14.9 \\
Primary & 215 & 12.2 \\
Middle & 148 & 8.4 \\
High & 320 & 18.2 \\
PUC & 144 & 8.2 \\
Graduate & 560 & 32.0 \\
PG & 102 & 5.8 \\
Occupation & & \\
Professional & 257 & 14.7 \\
Skilled & 38 & 2.2 \\
Unskilled & 303 & 17.3 \\
Clerical & 446 & 25.5 \\
Housewives & 370 & 21.1 \\
Students & 332 & 19.0 \\
Retired & 4 & 0.2 \\
\hline
\end{tabular}

Education and occupation classification based on Kuppuswamy scale ${ }^{4}$

source of information about tooth decay was from grandparents (23.2\%), and about control of tooth decay (21.6\%), periodontal problems $(21.8 \%)$, control of periodontal problems $(22.6 \%)$, about oral cancer (34\%), and control of oral cancer $(30.6 \%)$ was from friends.

Out of total answers, the majority found for source of oral health information was parents (21.1\%) followed by friends (20.1\%), television (19.5\%), grandparents (16.6\%), school books/teachers (10.2\%), newspaper (6.1\%), and minor was hospitals (6.1\%).

Table 3 shows the descriptive statistics about the paramount source of oral health information according to gender. It shows significant ( $p$ value $=0.001$ ) for all questions. Majority of males answered that parents were the major source of information about brushing technique (32.9\%), control of tooth decay (10.2\%), oral cancer (8.2\%), and control of oral cancer (13.3\%). Majority of females answered that parents were the major source of information about tooth decay (15\%), periodontal problems (7.8\%), and control of periodontal problems (9.1\%).

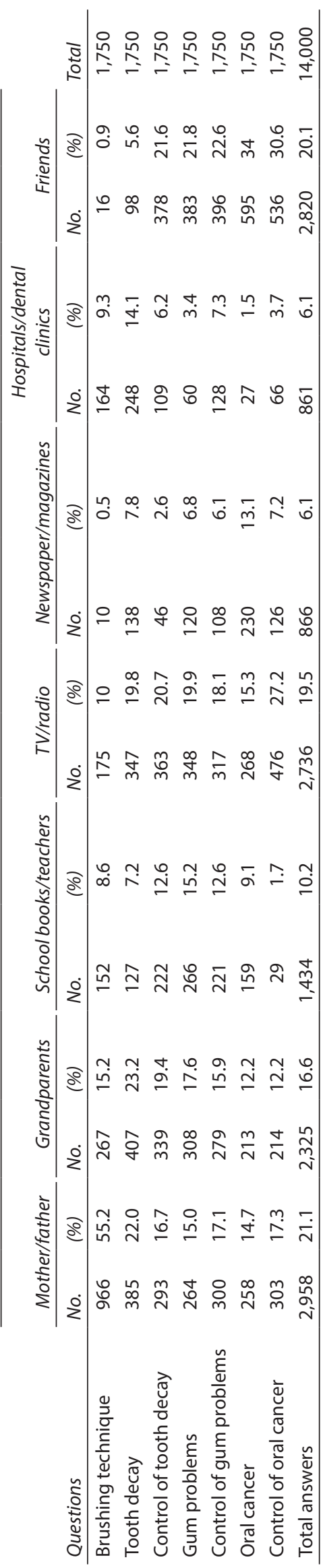


Table 3: The paramount source of oral health information according to gender

\begin{tabular}{|c|c|c|c|c|c|c|c|c|c|}
\hline \multirow[b]{2}{*}{ Questions } & \multirow[b]{2}{*}{ Gender } & \multicolumn{7}{|c|}{ Source of information in percentage } & \multirow[b]{2}{*}{$p$ value } \\
\hline & & $\begin{array}{l}\text { Mother/ } \\
\text { father }\end{array}$ & Grandparents & $\begin{array}{l}\text { School } \\
\text { books/ } \\
\text { teachers }\end{array}$ & TV/radio & $\begin{array}{l}\text { Newspaper/ } \\
\text { magazines }\end{array}$ & $\begin{array}{l}\text { Hospitals/ } \\
\text { dental clinics }\end{array}$ & Friends & \\
\hline \multirow[t]{2}{*}{ Brushing technique } & $\mathrm{F}$ & 22.3 & 10.7 & 7.5 & 1.9 & 0.3 & 1.6 & 0.3 & ${ }^{*} 0.001$ \\
\hline & M & 32.9 & 4.6 & 1.1 & 8.1 & 0.3 & 7.8 & 0.6 & \\
\hline \multirow[t]{2}{*}{ Tooth decay } & $\mathrm{F}$ & 15 & 7.3 & 3.7 & 6.5 & 0.5 & 7.1 & 2.5 & $* 0.002$ \\
\hline & M & 7 & 16 & 3.6 & 13.4 & 5.4 & 7.0 & 3.1 & \\
\hline \multirow[t]{2}{*}{ Control of tooth decay } & $\mathrm{F}$ & 6.6 & 5.3 & 5.4 & 9.5 & 2.2 & 2.8 & 12.8 & ${ }^{*} 0.001$ \\
\hline & M & 10.2 & 14.1 & 7.3 & 11.3 & 0.5 & 3.4 & 8.8 & \\
\hline \multirow[t]{2}{*}{ Gum problems } & $\mathrm{F}$ & 7.8 & 9.5 & 6.3 & 8.8 & 1.3 & 3.3 & 10.1 & ${ }^{*} 0.001$ \\
\hline & M & 7.3 & 8.1 & 8.9 & 11.1 & 5.5 & 95.7 & 11.8 & \\
\hline \multirow[t]{2}{*}{ Control of gum problems } & $\mathrm{F}$ & 9.1 & 7.6 & 4.5 & 6 & 0.8 & 14.8 & 1.0 & $* 0.002$ \\
\hline & M & 8.1 & 8.3 & 8.2 & 12.1 & 9.1 & 1.0 & 18.2 & \\
\hline \multirow[t]{2}{*}{ Oral cancer } & $\mathrm{F}$ & 6.6 & 6.1 & 8.2 & 3.3 & 4.0 & 0.6 & 15.8 & ${ }^{*} 0.001$ \\
\hline & M & 8.2 & 6.1 & 0.9 & 12.1 & 9.1 & 1.0 & 18.2 & \\
\hline \multirow[t]{2}{*}{ Control of oral cancer } & $\mathrm{F}$ & 4.0 & 7.5 & 0.6 & 11.4 & 0.7 & 17.3 & 2.9 & ${ }^{*} 0.001$ \\
\hline & M & 13.3 & 4.7 & 1.0 & 15.8 & 6.5 & 13.3 & 0.9 & \\
\hline
\end{tabular}

${ }^{*} p<0.01$ (highly significant); $p<0.05$ (significant); $p>0.05$ (nonsignificant)

Majority of males answered that television/radio was the major source of oral health information when compared to females. Hospitals were the equal source for both the genders for oral health information. Friends were the major source for males when compared to females about oral health information.

\section{Discussion}

The present study was conducted to assess the paramount source of oral health information among outpatients attending one of the dental colleges in Bengaluru city, Karnataka, India. To the best of our knowledge, this study represents the first of its kind that explored among general population in Bengaluru.

Beliefs are permanent, stable, and almost unchanging; they are usually derived from our parents, grandparents, and other people we respect. We accept beliefs, without trying to prove that they are true. Every community has its own beliefs as beliefs are held strongly; they are often difficult to change. They can be harmful, helpful, or neutral. ${ }^{5}$ But sometimes behavioral changes occur in the man's life at any stage. Therefore, it is very important to inculcate the basic knowledge at childhood level about oral healthcare. Hence, source of information plays a major role in everyone's life.

This study provides important new data to the evidence base related to source of oral health information among general population. To our knowledge, there are very few Indian studies involving general population. The questionnaires particularly focus on the source of dental caries, periodontal problems, oral cancer, and brushing technique that are likely to have influence on oral health knowledge of people.

The current study shows that the majority of the study population had source for oral health information from parents and friends (21.1\% and 20.1\%). The study results are in consensus with the study conducted by Anwar et al. ${ }^{1} 2012$ and Kanduluru et al. ${ }^{5} 2011$, wherein $39.6 \%$ and $33.7 \%$ respondents, respectively, chose parents as the main source of information. In a study conducted by Wyne et al., ${ }^{6} 34.2 \%$ of the Saudi population responded that they obtain oral health information from dentist which is in contrast with our study.
A study conducted by Al-Darwish et al. ${ }^{3} 2011$, among schoolchildren in Quatar, showed that parents (69.2\%) were the major source of information about brushing technique. Among them males were $67 \%$ and females were $71.5 \%$. These results are in contradictory with the current study, where only $21.1 \%$ of parents were found as major source of oral health information. There as on could be due to lack of oral health information among parents and the optimal way to raise children's oral health awareness would be to furnish accurate information to parents.

A study done by Archana et al. ${ }^{7}$ in 2010 found the media (33.6\%) as major source of information, and study conducted by Dilip et al. ${ }^{8}$ in 2005 found magazines (17\%) as major source of information among patients who visited dental clinic. These study results are in contradictory with the current study. The reason could be less usage of mass media by the people participated in the study.

The reason for dentists and hospitals to be found as a minor source of oral health information might be either because the dental professionals busy schedules, lack of interest, deficient policies of the government, or less frequent visit to the dentist by the people in India.

A study done by Anwar et al. ${ }^{1}$ in 2012 Karachi, found that parents (39.6\%) were the major source of information about brushing technique, whereas in the present study (55.2\%), more than half of the participants said that parents were the major source of information. This could be due to the cultural background differences in countries.

A study done by Anwar et al. ${ }^{1}$ in 2012 Karachi, found that parents $(37.2 \%)$ were the major source of information about dental caries, whereas only $22 \%$ of participants said that parents are the major source of information about dental caries in the present study.

Change in health beliefs requires acquiring life skills and changes in attitude, and not just enhanced cognition or acquiring information. Information transfer alone without emphasis or focus on attitudinal changes and environmental modification will have limited impact and is a major public health challenge. Hence, as a public health dentist, we have to approach the target source to give 
oral health education to the people. This will help to reduce the burden of prevalence and incidence of oral diseases at the earliest.

\section{Strengths and Limitations}

The present study provides the framework for the oral health activities which appears essentially to be aiming at prevention and oral health education rather than on general health aid. It can act as a stepping stone for further organized oral health programs by private as well as government bodies. The study participants were recruited from different educational backgrounds and occupations; this represents the existing scenario of oral health information.

As this study is cross-sectional, it evaluates source and outcome at the same point in time introducing the problem of temporal ambiguity and incapability in proving a causal relationship. This study involved only outpatients of dental college; hence, further studies are recommended in a cross section of the population represented by all sections of the society.

\section{Recommendations}

Scientific information about oral health should be included in health educational packages directed at different subpopulations within communities. Public health dentists can also utilize the opportunity to educate parents and grandparents about their role in improving their children oral health. Health authorities can target this paramount source to provide health information to reach their millennium development goals.

\section{Conclusion}

The study concludes that majority of the study population has parents and friends as a source of oral health information followed by television, grandparents, school books/teachers, newspaper/ magazines, and least was by hospitals. Hence, there is a need to target these groups to reinforce the health education and also need to utilize the hospitals, schoolteachers, and media to provide health education and enhance the oral health knowledge of public.

\section{References}

1. Anwar MJ, Ali SM, Leghari MA, et al. Oral hygiene knowledge and source of information among 12 to 16 years old Karachi school children. Pakistan Oral and Dental J 2015;35(2):258-261.

2. Park K. Park's text book of preventive \& social medicine. 20th ed., Jabalpur: Bhanotpublishers; 2009. p. 589.

3. Al-Darwish MS, Abuhassna M, Al-Thomairy SA. Oral health knowledge and sources of oral health information among school children in Qatar. J Dent Health Oral Disord Ther 2015;2(3):00049.DOI: 10.15406/ jdhodt.2015.02.00049.

4. Patro BK, Kathiresan J, Gupta PK. Kuppuswamy's socioeconomic status scale 2010-the need for periodic revision. Indian J Pediatr 2012;79(3):395-396. DOI: 10.1007/s12098-011-0517-7.

5. Kanduluru A, Manasa S, Reddy MT. Assessment of misconceptions about oral health care and their source of information among out patients attending dental college in Bangalore-a cross sectional study. J Indian Assoc Public Health Dent 2013;11(4):77-81.

6. Wyne AH, Chohan AN, Al-Qedrah A. Oral health knowledge and sources of information among male secondary school children in Riyadh. Saudi Dent J. 2005;17:140--145.

7. Archana S, Jagat $S$. Factors influencing choice of oral hygiene products used among population of Udaipur, India. Int J Dent Clin 2010;2(2):7-12.

8. Dilip CL. Health status, treatment requirements, knowledge and attitude towards oral health of police recruits in Karnataka. J Indian Assoc Public Health Dent 2005;5:20-34. 